\title{
Analysis Of Passivated A-286 Stainless Steel Surfaces for Mass Spectrometer Inlet Systems By Auger Electron and X-Ray Photoelectron Spectroscopy
}

\author{
Henry Ajo, Donnie Blankenship, and Elliot Clark
}

Savannah River National Laboratory (SRNL), Aiken, South Carolina, USA

Although the stainless steel surface has long been a subject of study [1] due to its technological relevance, the surface passivation of A-286 [2] has not been investigated as extensively as more common stainless steels [1]. A-286 (UNS 66286) is notable in its difference from the type 304 and 316 stainless steels more commonly used in vacuum systems, in that the concentration of nickel in A-286 is greater than the concentration of chromium and the nickel content is quite high at 23-25 atomic percent[3]. Another important difference is the presence of 2.2-2.7 atomic percent titanium. In previous work [2] with passivated A-286, titanium was found at the surface in concentrations exceeding its bulk composition. Otherwise though, the A-286 depth profile [2] appears qualitatively similar to those seen in 300 series stainless steels [2,4-9], with an adventitious carbon layer that is gradually sputtered away and an oxide layer that is indicative of the passivated layer [2,4-9]. Previously, the oxide layer seen in A-286 was $4 \mathrm{~nm}$ [2]. The oxide layers for untreated 300 series stainless steels ranged from 1 to $3.5 \mathrm{~nm}$ [4-6], while the oxide layer for specially treated 300 series stainless steels ranged from $25 \mathrm{~nm}$ to 2 microns thick [5-8]. Scanning electron microscopy (SEM) images from the 300 series stainless steels show a relatively smooth and flat untreated surface [4-6], except in reference [7], which shows a relatively rough surface for the untreated stainless steel. However, with passivation treatment, these surfaces become notably rougher [5-7] except for a flow polishing treatment in ref. [4].

A-286 stainless steel coupons approximately 0.5 " in diameter and 0.125 " thick were passivated with five different surface treatments and an untreated coupon was left as a control. These surface treatments are being explored for use in mass spectrometer inlet systems, where it is very important to have inlet systems which do not change the composition of the analyte measured. These coupons were made to allow surface analysis of the surface treatments using well-known surface analysis techniques. Depth profiles using Auger electron spectroscopy (AES) and X-ray photoelectron spectroscopy (XPS) were performed on these coupons to characterize the surface and near surface regions. Scanning electron microscope (SEM) images were collected using the AES instrument. All of the surface treatments studied here appear to change the surface morphology dramatically, as evidenced by lack of tool marks on the treated samples. In terms of the passivation treatment, Vendors A-D appeared to have oxide layers that were very similar in thickness to each other (0.7-0.9 nm thick) as well as the untreated samples (the untreated sample oxide layers appeared to be somewhat larger, see Table 2). Vendor E's silicon coating appears to be on the order of $200 \mathrm{~nm}$ thick.

Morphologically, all of the surface treatments studied here appear to change the surface morphology dramatically, as evidenced by lack of tool marks on the treated samples. Vendors A, B, and C had relatively smooth morphologies, while Vendor D's surface treatment resulted in calcium-rich "mountains" on the surface and Vendor E's treatment resulted in a bumpy surface that included at least one area that was missing from the coating, leaving the stainless steel exposed. It should also be noted that Vendor B's treatment appeared to leave large amounts of carbon on the surface, as evidenced by SEM (not shown) and XPS calculations of adventitious carbon thickness (Table 1). In terms of the passivation treatment, Vendors A-D appeared to have oxide layers that were very similar in thickness to 
each other as well as the untreated samples (Table 1 and Table 2); although the untreated sample oxide layers appeared to be possibly larger. Vendor E's silicon coating appears to be on the order of $200 \mathrm{~nm}$ $\mathrm{SiO}_{2}$ equivalents thick. In terms of the chemistry of the coatings, they also appear very similar with some elements found in some AES depth profiles at very low concentrations that do not appear in others. However, at those low concentrations, these differences could be a result of sample handling.

\section{References:}

[1] R.O. Adams, J. Vac. Sci. Technol. A 1 (1983), p.12.

[2] W. A. Swansinger and R. Bastasz, J. Nucl. Mater. 85 \& 86 (1979), p. 335.

[3] J. R. Davis, "Surface Engineering" in ASM Handbook 5 (ASM International, 1994).

[4] J.T. Gill, W.E. Moddeman, and R.E. Ellefson, J. Vac. Sci. Technol. A 1 (1983), p.869.

[5] A. Vesel, M. Mozetic, A. Drenik, N, Hauptman, and M. Balat-Pichelin, Appl. Surf. Sci. 255 (2008), p. 1759.

[6] P. Stefanov, D. Stoychev, M. Stoycheva, A. R. Gonzalez-Elipe, and Ts. Marinova, Surf. Interface Anal. 28 (1999), p.106.

[7] D. Mandrino, M. Godec, M. Torkar, and M. Jenko, Surf. Interface Anal. 40 (2008), p.285.

[8] P.V. A. Ignatova, St. Van Dyck, R. Grotzschel, and W. Moller, Surf. Interface Anal. 38 (2006), p.396.

[9] T. Hryniewicz, K. Rokosz, and R. Rokicki, Corros. Sci. 50 (2008) p. 2676.

[10] This work was funded by a Plant Directed Research and Development grant.

\begin{tabular}{||l|l|l||}
\hline Sample & \multicolumn{1}{|c||}{$\begin{array}{c}\text { Thickness } \\
\text { Adventitious } \\
\text { Carbon }(\mathrm{nm})\end{array}$} & $\begin{array}{c}\text { Thickness } \mathrm{Cr}_{2} \mathrm{O}_{3} \\
(\mathrm{~nm})\end{array}$ \\
\hline Vendor B & 5.6 & 0.9 \\
\hline Vendor C & 1.8 & 0.9 \\
\hline Vendor D & 2.4 & 0.7 \\
\hline
\end{tabular}

Table 1. Calculated adventitious carbon and $\mathrm{Cr}_{2} \mathrm{O}_{3}$ thicknesses for Vendors $\mathrm{B}, \mathrm{C}$, and D.

\begin{tabular}{|c|c|c|c|}
\hline Sample & Omax (nm) & Omax/2 (nm) & Thickness* (nm) \\
\hline Untreated 1 & 2 & 6 & 4 \\
\hline Untreated 2 & 2 & 4.7 & 2.7 \\
\hline Vendor A & 1.5 & 3.7 & 2.2 \\
\hline Vendor B & 1.3 & 3.6 & 2.3 \\
\hline Vendor C & 0.6 & 3.1 & 2.5 \\
\hline Vendor D & 0.9 & 3.2 & 2.3 \\
\hline
\end{tabular}

Table 2. AES depth profile oxide thickness calculation. 